\title{
TITLE:
}

\section{List of recorded species}

$\operatorname{AUTHOR}(S):$

OHGAKI, SHUN-ICHI; KOMEMOTO, KEN-ICHI; FUNAYAMA, NOBUTAKA

\section{CITATION:}

OHGAKI, SHUN-ICHI ...[et al]. 2. List of recorded species. Publications of the Seto Marine Biological Laboratory. Special Publication Series 2011, 11: 4-14

\section{ISSUE DATE:}

2011

URL:

http://hdl.handle.net/2433/159498

RIGHT: 
2. List of recorded species

Code no. Species name

Japanese name

Class Polyplacophora

多板綱

Family Ischnochitonidae

$$
\begin{aligned}
& \text { ウスヒザラガイ科 } \\
& \text { ホソウスヒザラガイ } \\
& \text { ウスヒザラガイ } \\
& \text { ヒゲヒザラガイ科 } \\
& \text { ババガセ } \\
& \text { クサズリガイ科 } \\
& \text { ヒザラガイ } \\
& \text { リュウキュウヒザラガイ } \\
& \text { ニシキヒザラガイ } \\
& \text { ケハダヒザラガイ科 } \\
& \text { ヒメケハダヒザラガイ } \\
& \text { ビロウドヒザラガイ } \\
& \text { ケムシヒザラガイ科 } \\
& \text { ケムシヒザラガイ }
\end{aligned}
$$

5 Acanthopleura loochooana (Broderip \& Sowerby)

6 Onithochiton hirasei Pilsbry

Family Acanthochitonidae

Class Gastropoda

腹足綱

Family Patellidae

ツタノハガイ科

10 Scutellastra flexuosa (Quoy \& Gaimard)

ツタノ八

Family Nacellidae

$$
\begin{aligned}
& \text { ヨメガカサガイ科 } \\
& \text { ベッコウガサ } \\
& \text { マツバガイ } \\
& \text { ヨメガカサ }
\end{aligned}
$$

ユキノカサガイ科

ヒメコザラ 
15 Patelloida saccharina lanx (Reeve)

16 Lottia langfordi (Habe)

17 Lottia kogamogai Sasaki \& Okutani

18 Lottia tenuisculpta Sasaki \& Okutani

19 Lottia lindbergi Sasaki \& Okutani

20 Nipponacmea fuscoviridis (Teramachi)

21 Nipponacmea gloriosa (Habe)

22 Nipponacmea nigrans (Kira)

23 Nipponacmea schrenckii (Lischke)

Family Haliotidae

24 Haliotis discus discus Reeve

25 Haliotis diversicolor aquatilis Reeve

26 Haliotis varia Linnaeus

Family Fissurellidae

27 Tugali decussata A. Adams

28 Montfortula picta (Dunker)

29 Macroschisma dilatatum (A. Adams)

30 Macroschisma sinense (A. Adams)

Family Trochidae

31 Chlorostoma lischkei Tapparone-Canefri

32 Chlorostoma turbinatum A. Adams

33 Chlorostoma xanthostigma A. Adams

34 Omphalius nigerrimus (Gmelin)

35 Omphalius pfeifferi (Philippi)

36 Omphalius rusticus (Gmelin)

37 Trochus histrio Reeve

38 Trochus maculatus Linnaeus

39 Trochus rota Dunker

40 Tectus conus (Gmelin)

41 Tectus pyramis (Born)

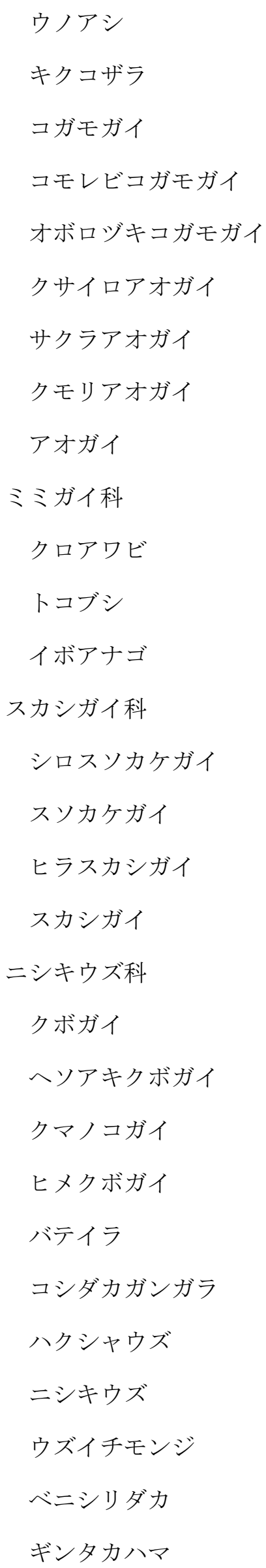


42 Eurytrochus cognatus (Pilsbry)

43 Fossarina picta A. Adams

44 Monodonta labio confusa Tapparone-Canefri

45 Monodonta perplexa perplexa Pilsbry

46 Cantharidus callichroa (Philippi)

47 Cantharidus japonicus (A. Adams)

48 Diloma suavis (Philippi)

49 Broderipia iridescens (Broderip)

50 Stomatella impertusa (Burrow)

51 Thalotia attenuatus (Jonas)

52 Calliostoma unicum (Dunker)

53 Conotalopia mustelina (Gould)

Family Turbinidae

54 Angaria neglecta Poppe \& Goto

55 Collonista amakusaensis Habe

56 Collonista glareosa Gould,

57 Bothropoma pilulum (Dunker)

58 Astralium haematragum (Menke)

59 Astralium heimburgi (Dunker)

60 Turbo coronatus coreensis (Recluz)

61 Turbo stenogyrus (Fischer)

62 Phasianella solida (Born)

Family Neritidae

63 Nerita albicilla Linnaeus

64 Nerita japonica Dunker

65 Nerita plicata Linnaeus

Family Phenacolepadidae

66 Phenacolepas unguiformis (Gould)

Family Cerithiidae

67 Cerithium citrinum Sowerby

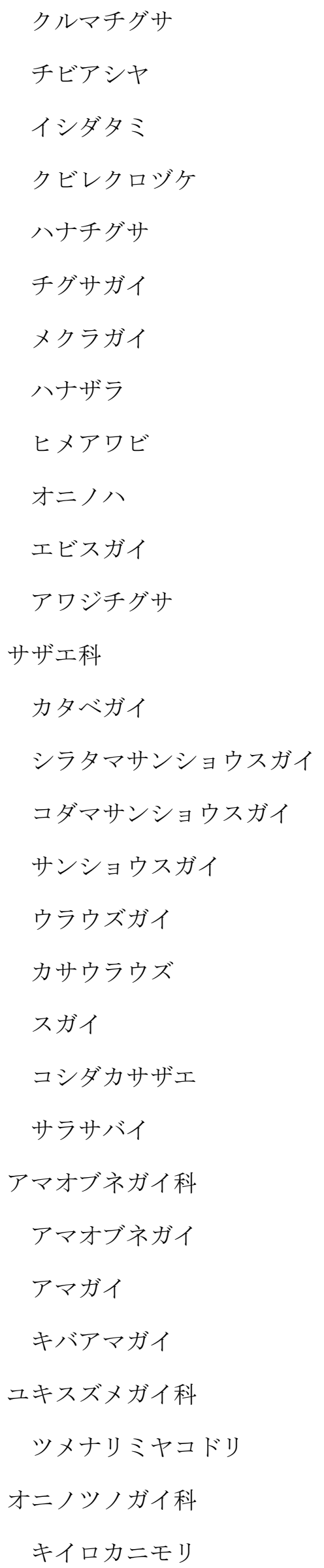


68 Cerithium lifuense Melvill \& Standen

69 Cerithium variegatum Habe \& Oyama

70 Clypeomorus bifasciata (Sowerby)

71 Ittibittium parcum (Gould)

Family Dialidae

72 Diala semistriata (Philippi)

Family Planaxidae

73 Planaxis sulcatus (Born)

74 Fossarus trochlearis (A. Adams)

Family Littorinidae

75 Littoraria pintado (Wood)

76 Littoraria undulata (Gray)

77 Peasiella habei Reid \& Mak

78 Nodilittorina radiata (Souleyet)

79 Nodilittorina trochoides (Gray)

80 Nodilittorina vidua (Gould)

81 Littorina brevicula (Philippi)

Family Barleeidae

82 Barleeia angustata (Pilsbry)

Family Rissoidae

83 Schwartziella zeltnerioides (Yokoyama)

Family Strombidae

84 Strombus luhuanus Linnaeus

85 Strombus mutabilis (Swainson)

Family Hipponicidae

86 Hipponix conica (Schumacher)

87 Hipponix foliacea ( Quoy \& Gaimard)

88 Hipponix trigona (Gmelin)

Family Calyptraeidae

89 Crepidula gravispinosus (Kuroda \& Habe)

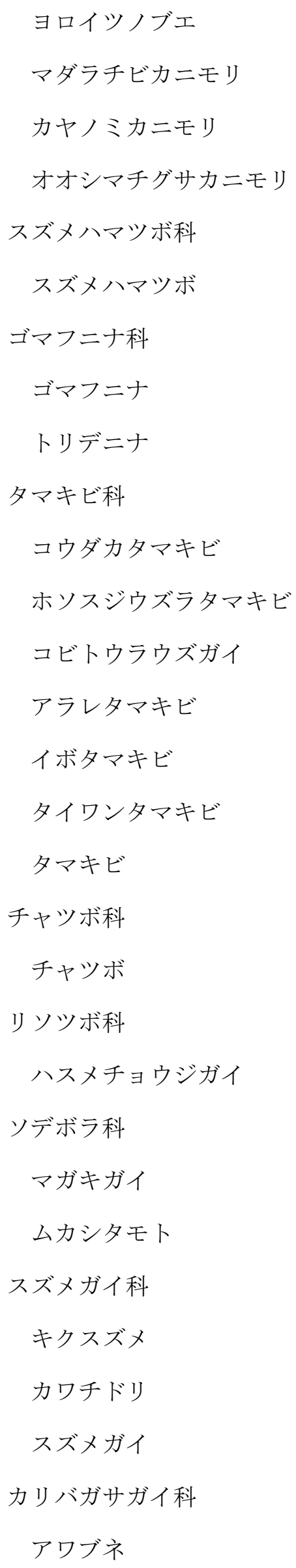


90 Crepidula onyx Sowerby

Family Vermetidae

91 Dendropoma dragonella (Okutani)

92 Dendropoma planorbis (Dunker)

93 Serpulorbis daidai Scheuwimmer \&Nishiwaki

94 Serpulorbis imbricatus (Dunker)

Family Cypraeidae

95 Cypraea annulus Linnaeus

96 Cypraea arabica asiatica (Schilder \& Schilder)

97 Cypraea artuffeli Jousseaume

98 Cypraea boivinii Kiener

99 Cypraea caputserpentis Linnaeus

100 Cypraea clandestina clandestina Linnaeus

101 Cypraea errones errones Linnaeus

102 Cypraea fimbriata fimbriata Gmelin

103 Cypraea gracilis Gaskoin

104 Cypraea helvola helvola Linnaeus

105 Cypraea labrolineata Gaskoin

106 Cypraea limacina limacine Lamarck

107 Cypraea listeri Gray

108 Cypraea moneta Linnaeus

109 Cypraea poraria Linnaeus

110 Cypraea vitellus Linnaeus

Family Triviidae

111 Erato callosa (A. Adams \& Reeve)

Family Velutinoidae

112 Lamellaria kiiensis Habe

Family Naticidae

113 Natica gualteriana Recluz

Family Ranellidae
シマメノウフネガイ

ムカデガイ科

$$
\begin{aligned}
& \text { タツノコヘビガイ } \\
& \text { ミジンムカデガイ } \\
& \text { オレンジへビガイ } \\
& \text { オオヘビガイ } \\
& \text { タカラガイ科 } \\
& \text { ハナビラダカラ } \\
& \text { ヤクシマダカラ } \\
& \text { チャイロキヌタ } \\
& \text { オミナエシダカラ } \\
& \text { ハナマルユキ } \\
& \text { カミスジダカラ } \\
& \text { ナツメモドキ } \\
& \text { ツマムラサキメダカラ } \\
& \text { メダカラ } \\
& \text { カモンダカラ } \\
& \text { ナシジダカラ } \\
& \text { シボリダカラ } \\
& \text { クロダカラ } \\
& \text { キイロダカラ } \\
& \text { アヤメダカラ } \\
& \text { ホシキヌタ } \\
& \text { シラタマガイ科 } \\
& \text { ザクロガイ } \\
& \text { ハナヅトガイ科 } \\
& \text { キシュウベッコウタマガイ } \\
& \text { タマガイ科 } \\
& \text { ホウシュノタマ } \\
& \text { フジツガイ科 }
\end{aligned}
$$


114 Charonia lampas sauliae (Linnaeus)

Family Epitoniidae

115 Gyroscala lamellosa (Lamarck)

116 Epitonium japonicum (Dunker)

117 Epitonium vigintifoliatum (Masahito \& Kuroda \& Habe)

118 Alexania inazawai (Kuroda)

Family Eulimidae

119 Vitreolina auratus (S. Hirase)

120 Vitreolina langfordi (Dall)

121 Apicalia habei (A. Adams)

Family Muricidae

122 Cronia margariticola (Broderip)

123 Ergalatax contractus (Reeve)

124 Muricodrupa fusca (Kuster)

125 Muricodrupa sp. (Eydoux \& Souleyet)

126 Maculotriton serriale (Deshayes)

127 Drupella fragum (Blainville)

128 Morula anaxeres (Kiener)

129 Morula funiculata (Reeve)

130 Morula granulata (Duclos)

131 Morula iostoma (Reeve)

132 Morula musiva (Kiener)

133 Morula sp.

134 Habromorula spinosa (H \& A. Adams)

135 Drupa ricinus hadari Emerson \& Cernohorsky

136 Mancinella bufo (Lamarck)

137 Mancinella echinata (Blainville)

138 Mancinella mancinella (Linnaeus)

139 Mancinella tuberosa (Roding)
ボウシュウボラ

イトカケガイ科

ネジガイ

ヒメネジガイ

ハタエイトカケ

イナザワハベガイ

ハナゴウナ科

キンイロセトモノガイ

ムラサキウニヤドリニナ

ヤツデヒトデヤドリニナ

アッキガイ科

ウネレイシダマシ

ヒメヨウラク

レイシダマシモドキ

コウシレイシダマシ

ゴマフヌカボラ

ヒメシロレイシダマシ

ウネシロレイシダマシ

クロフレイシダマシ

レイシダマシ

イトマキレイシダマシ

シマレイシダマシ

ニッポンレイシダマシ

トゲレイシダマシ

シロイガレイシ

タイワンレイシ

ウニレイシ

キナレイシ

ツノレイシ 
140 Purpula panama (Roding)

141 Thais bronni (Dunker)

142 Thais clavigera (Kuster)

143 Thais luteostoma (Holten)

144 Coralliophila squamosissima (Smith)

Family Columbellidae

145 Euplica scripta (Lamarck)

146 Anachis misera misera (Sowerby)

147 Pyrene flava (Bruguiere)

148 Pyrene testudinaria tylerae (Gray)

149 Mitrella bicincta Gould

150 Zafra pumila (Dunker)

151 Zafra sinensis (Sowerby)

Family Nassariidae

152 Niotha livescens (Philippi)

153 Niotha semisulcata (Rousseau)

154 Telasco sufflatus (Gould)

155 Telasco velatus (Gould)

156 Reticunassa fratercula (Dunker)

Family Buccinidae

157 Enzinopsis menkeana (Dunker)

158 Japeuthria ferrea (Reeve)

Family Mitridae

159 Strigatella litterata (Lamarck)

160 Strigatella paupercula (Linnaeus)

161 Strigatella scutulata (Gmelin)

Family Conidae

162 Conus coronatus Gmelin

163 Conus miliaris Sowerby

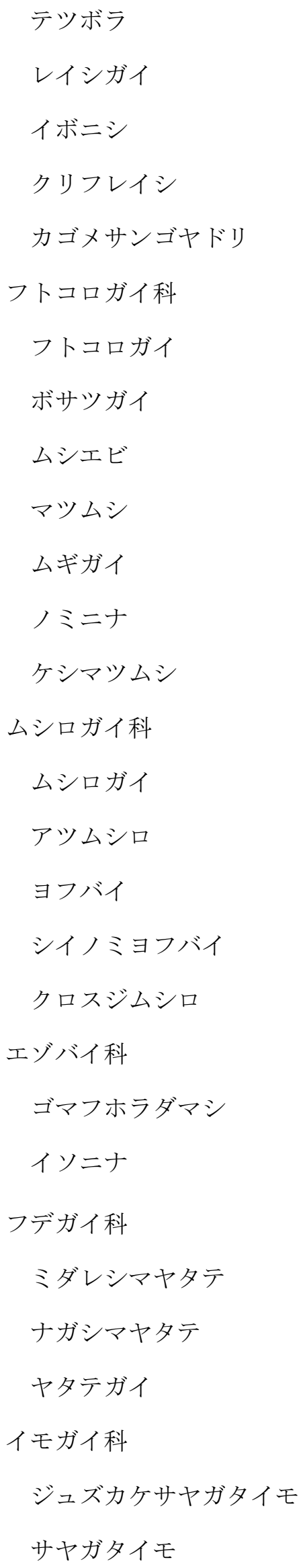


164 Conus ebraeus Linnaeus

165 Conus lividus Hwass

166 Conus musicus Hwass

167 Conus sponsalis Hwass

Family Turridae

168 Hemicythara octangulata (Dunker)

169 Lienardia malleti (Recluz)

Family Architectonicidae

170 Heliacus enoshimensis (Melvill)

Family Pyramidellidae

171 Paracingulina triarata (Pilsbry)

Family Bullinidae

172 Bullina lineata (Gray)

Family Hydatinidae

173 Hydatina physis (Linnaeus)

Family Aglajidae

174 Chelidonura inornata (Baba)

Family Haminoeidae

175 Haloa japonica (Pilsbry)

Family Smaragdinellidae

176 Smaragdinella sieboldi A. Adams

Family Bullidae

177 Bulla ventricosa Gould

Family Hermaeidae

178 Ercolania boodleae (Baba)

Family Aplysiidae

179 Aplysia dactylomela Rang

180 Aplysia juliana Quoy \& Gaimard

181 Aplysia kurodai (Baba)

182 Aplysia oculifera Adams \& Reeve

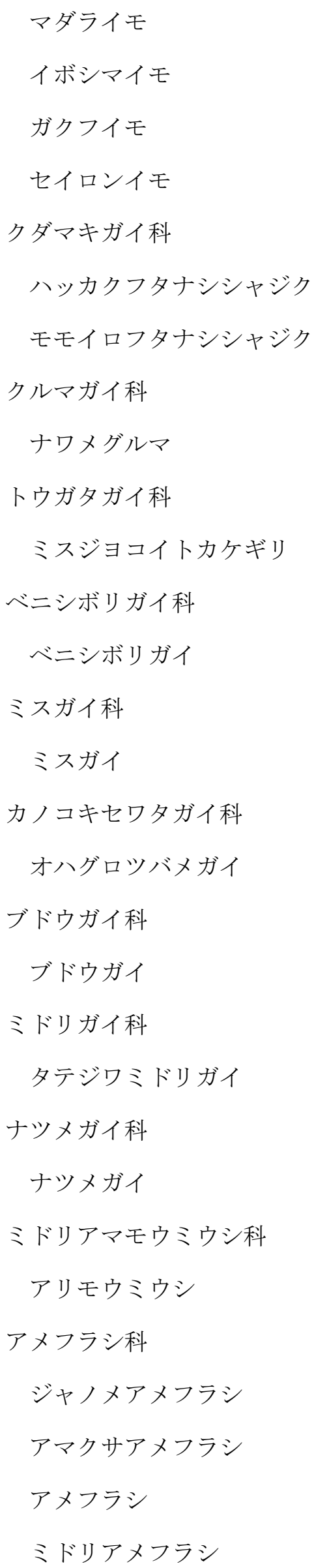


183 Aplysia parvula Guilding

184 Dolabella auricularia (Lightfoot)

Family Goniodorididae

185 Goniodoris castanea Alder \& Hancock

Family Triophidae

186 Kalinga ornata Alde \& Hancock

Family Chromodorididae

187 Hypselodoris festiva (A. Adams)

Family Dorididae

188 Discodoris concinna (Alder \& Hancock)

189 Doriopsis granulosa Pease

190 Platydoris speciosa (Abraham)

191 Platydoris tabulate (Abraham)

Family Dendrodorididae

192 Dendrodoris arborescens (Collingwood)

193 Doriopsilla miniata (Alder \& Hancock)

Family Tethydidae

194 Melibe papillosa (de Filippi)

Family Aeolidiidae

195 Spurilla chromosoma Cockerell \& Eliot

Family Onchidiidae

196 Onchidella kurodai (Taki)

197 Peroniasp.

Family Siphonariidae

198 Siphonaria acmaeoides Pilsbry

199 Siphonaria japonica (Donovan)

200 Siphonaria sirius Pilsbry

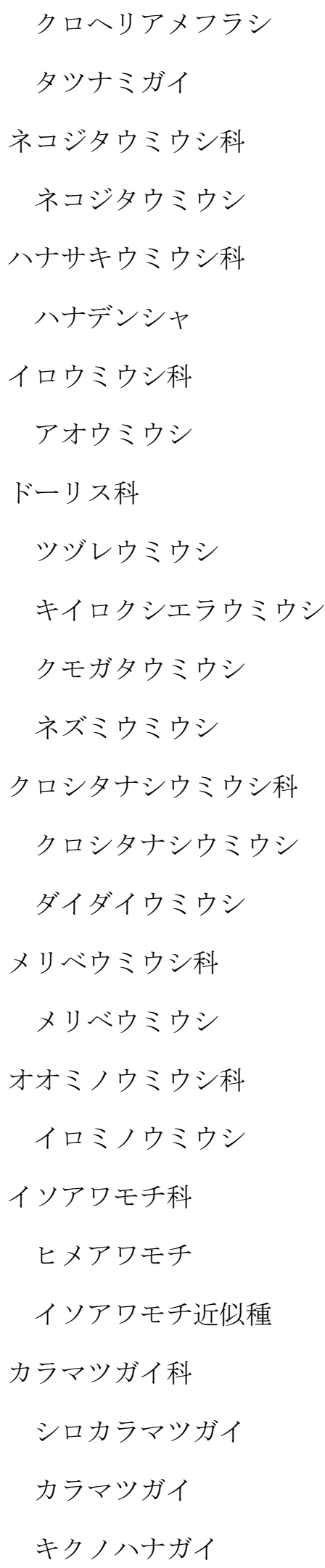


201 Nucula paulula A. Adams

Family Arcidae

202 Arca avellana Lamarck

203 Arca boucardi Josseaume

204 Barbatia fusca (Bruguiere)

205 Barbatia lima (Reeve)

206 Barbatia stearnsii (Pilsbry)

207 Barbatia virescens (Reeve)

208 Arcopsis symmetrica (Reeve)

Family Mytilidae

209 Mytilus coruscus Gould

210 Mytilus galloprovincialis Lamarck

211 Xenostrobus atratus (Lischke)

212 Hormomya mutabilis (Gould)

213 Septifer bilocularis (Linnaeus)

214 Septifer virgatus (Wiegmann)

215 Modiolus auriculatus (Krauss)

216 Modiolus nipponicus (Oyama)

217 Musculus pusio (A. Adamas)

Family Pteriidae

218 Pinctada maculata (Gould)

219 Pinctada margaritifera (Linnaeus)

220 Pinctada martensii (Dunker)

Family Isognomonidae

221 Isognomon acutirostris (Dunker)

222 Isognomon legumen (Gmelin)

Family Limidae

223 Lima vulgaris Link

Family Spondylidae

224 Spondylus barbatus Reeve

$$
\text { マメクルミガイ }
$$

フネガイ科

フネガイ

コベルトフネガイ

ベニエガイ

エガイ

ハナエガイ

カリガネエガイ

ミミエガイ

イガイ科

イガイ

ムラサキイガイ

クログチ

ヒバリガイモドキ

クジャクガイ

ムラサキインコ

リュウキュウヒバリガイ

ヒバリガイ

チビタマエガイ

ウグイスガイ科

ミドリアオリ

クロチョウガイ

アコヤガイ

マクガイ科

ヘリトリアオリ

シロアオリ

ミノガイ科

ミノガイ

ウミギク科

ウミギク 
Family Anomiidae

225 Plicatula australis Lamarck

Family Gryphaeidae

226 Hyotissa chemnitzi (Hanley)

Family Ostreidae

227 Crassostrea gigas (Thunberg)

228 Crassostrea nippona (Seki)

229 Saccostrea kegaki Torigoe \& Inaba

230 Saccostrea mordax (Gould)

231 Dendostrea crenulifera (Sowerby)

Family Lasaeidae

232 Lasaea undulata (Gould)

Family Carditidae

233 Cardita leana Dunker

Family Chamidae

234 Chama japonica Lamarck

Family Petricolidae

235 Claudiconcha japonica (Dunker)

Family Veneridae

236 Gafrarium dispar (Dillwyn)

237 Gafrarium divaricatum (Gmelin)

238 Protothaca jedoensis (Lischke)

239 Ruditapes variegatus (Sowerby)

240 Irus mitis (Deshayes)

241 Irus macrophyllus (Deshayes)

Family Hiatellidae

242 Hiatella orientalis (Yokoyama)

$$
\begin{aligned}
& \text { ナミマガシワ科 } \\
& \text { カスリイシガキモドキ } \\
& \text { ベッコウガキ科 } \\
& \text { ベニガキ } \\
& \text { イタボガキ科 } \\
& \text { マガキ } \\
& \text { イワガキ } \\
& \text { ケガキ } \\
& \text { オハグロガキ } \\
& \text { ノコギリガキ } \\
& \text { チリハギガイ科 } \\
& \text { チリハギガイ } \\
& \text { トマヤガイ科 } \\
& \text { トマヤガイ } \\
& \text { キクザルガイ科 } \\
& \text { キクザル } \\
& \text { イワホリガイ科 } \\
& \text { セミアサリ } \\
& \text { マルスダレガイ科 } \\
& \text { イナミガイ } \\
& \text { ケマンガイ } \\
& \text { オニアサリ } \\
& \text { ヒメアサリ } \\
& \text { マツカゼガイ } \\
& \text { ハネマツカゼ }
\end{aligned}
$$

Note: Only the species found alive are listed. The Japanese names are according to Okutani (2000). 